\title{
Vibration diagnostic of electric motor roller bearings
}

\author{
N. V. Hruntovich ${ }^{1, *}, N . V$. Hruntovich $^{1}, A . A$. Kapanski $^{1}, I . V$. Petrov $^{1}$, and E. E. Kostyleva ${ }^{2}$ \\ ${ }^{1}$ Sukhoi State Technical University of Gomel, Gomel, Republic of Belarus \\ ${ }^{2}$ Kazan State Power Engineering University, Kazan, Russia
}

\begin{abstract}
The low quality of the new rolling bearings leads to additional costs for electric motor repair, and additional expenses connected with the technological process, value of which can reach from several thousand to tens of thousand dollars. To increase detection, the reliability of rolling bearing defects of asynchronous motors, complex vibration diagnostics was used at informative frequencies in the vibration frequency and amplitude in the range of $5-5000 \mathrm{~Hz}$. Based on the diagnostic model of rolling bearings the software program "Tayamnitsa" is developed, which allows to calculate the diagnostic frequency corresponding to certain defects, determine the defect level and form a diagnostic table for defects. Vibration diagnostics of new and used rolling bearings have been conducted for various regional enterprises and power plants. It has been determined that $40-50 \%$ of used bearings are removed in good technical condition. When new bearings were diagnosed in the 500-5000 Hz range, only $48.4 \%$ of the bearings are considered serviceable due to the low accuracy class of metal processing and unacceptably high vibration level.
\end{abstract}

\section{Introduction}

Rolling bearings are elements of rotary mechanisms and their most vulnerable parts. Currently used methods for monitoring the technical condition of asynchronous motors during operation and repair involve complete or partial equipment disassembly $[1,2,3,4,5]$. This procedure disrupts the unit running-in and reduces the trouble-free operation period. The damage caused by periodic electric motor repair during operation is so large that the relevance of diagnosing rolling bearings of rotor mechanisms without their dismantling is of no doubt. One of the most important tasks to improve the electric motor efficiency is operation and maintenance due to actual condition, based on the data analysis and control of the technical condition parameters according to vibration diagnostics results. This is intended to eliminate unexpected breakdowns, ensure reliable mechanism operation and cost savings [6].

One of the main problems of electrical equipment vibration diagnostics is the choice of a method for assessing the technical condition.

There are manufacture and operational defects of rolling bearings $[6,7,8]$. The manufacture defects include rolling element out-of-roundness; inner ring ovality; clearance non-uniformity between rolling elements and rings (different diameters of the rolling elements), increased ring waviness.

The operational defects include: manufacture defects that lead to intensive wear of the rolling bearing units; outer ring skew; cracks on the inner ring; wear of the separator; non-uniform radial tension; wear of the rolling elements; grease contaminant; scorings; dints; corrosion; brinelling.

Nowadays six methods of assessing the technical condition of rolling bearings are used in practice.

In the research [6] theoretical bases of technical diagnostics of rolling bearings on a direct spectrum in the range of $5-5000 \mathrm{~Hz}$ are stated. Detection of defects in rolling bearings using the envelope method is described in details [9]. Technical diagnostics of rolling bearings is described based on the shock pulse analysis [10]. The problem solution of rolling bearing technical diagnostics on the general level in the range of $10-1000 \mathrm{~Hz}$ will inevitably lead to errors [11]. There are a number of articles in which the method of sparse wavelet decomposition of signals is used to analyze vibration spectra $[12,13]$.

The research objective is to test rolling bearings (new and used) on a diagnostic stand to identify their defects and the possibility of further operation based on the vibration spectrum analysis. The research method is the complex vibration diagnostics based on vibration frequency and amplitude.

\section{Methods}

The special vibroacoustic diagnostic stand for testing rolling bearings with an inner diameter of $25-160 \mathrm{~mm}$ is designed and manufactured. The stand can test new and used bearings based on frequency and amplitude. The stand consists of a frame, induction motor, slide bearing housing, which bolted to the frame. The rotation from the motor is transmitted with a belt drive to the sliding

\footnotetext{
* Corresponding author: gruntovich@tut.by
} 


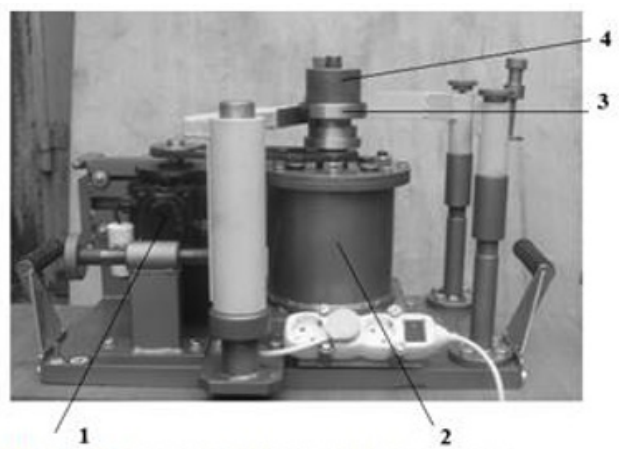

a) Rolling bearing diagnostic stand:

1- asynchronous motor with pulley;

2 - slid bearing housing;

3 - testing rolling bearing;

4 - clamping nut.

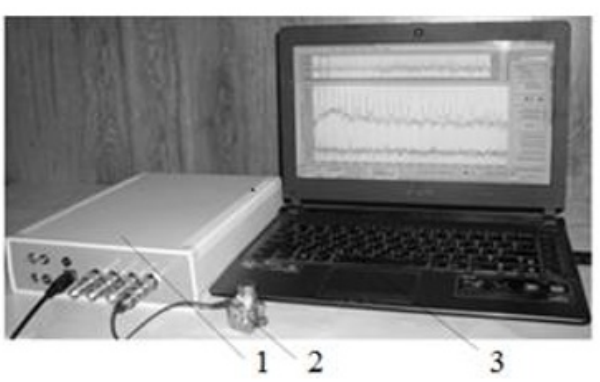

b) Computer multichannel diagnostic complex:

1 - multi channel matching device;

2 - acceleration vibration sensor;

3 - computer with the program "Tayamnitsa" (registration of signals, processing, issuing protocols).

Fig. 1. Vibrodiagnostic complex for diagnosing rolling bearings.

bearing shaft. The rolling bearing inner ring is clamped with special discs with a nut. The outer ring is clamped with two levers. On the stand, you can create a radial and axial rolling bearing load. Vibration acceleration sensor $(5-5000 \mathrm{~Hz}$ or $5-20000 \mathrm{~Hz})$ is mounted on the outer ring with a magnet. The sliding bearing shaft is fitted with mandrels for each rolling bearing size (Figure 1, a).

The signal from the vibration acceleration sensor is transmitted to the computer through the charge amplifier and the matching device (Figure 1, b). A single-phase or three-phase asynchronous motor can be installed on the stand (depending on the place of the experiment).

\section{Results}

Using the minimax criterion [6] a diagnostic model of rolling bearings and asynchronous motors has been developed. A mathematical model for the calculation of informative vibration frequencies is presented in table 1.

These spectra (Figure 2) can be analized using a special software program "Tayamnitsa" [14] with the defect report readout (Table 2).

The authors verified the effectiveness of the diagnostic program during field experiments.

The vibration diagnostics of the used bearings showed that $40-50 \%$ of the bearings are removed in good

Table 1. Defects of rolling bearings and vibration frequency.

\begin{tabular}{|c|c|c|c|}
\hline $\begin{array}{c}\text { The vibration frequency to } \\
\text { identify a defect }\end{array}$ & Type of defect & Formula & \multirow{7}{*}{$\begin{array}{l}\quad \text { The explanation of the formulas } \\
f_{r} \text { - the rotation frequency of AM rotor, } \\
\text { Hz. Adopted } 24,4 \mathrm{~Hz} \text {; } \\
R_{i r} \text { - working surface radius of the rolling } \\
\text { bearing inner ring, mm; } \\
r_{s} \text { - the radius of the rolling elements, } \\
\text { mm. } \\
f_{s} \text { - rotation frequency of the separator } \\
\text { relative to the center of the shaft, Hz; } \\
Z_{R} \text { - number of rolling elements; } \\
k_{1} \text { - the ratio of the working surface } \\
\text { circumference of the outer ring to the } \\
\text { ball circumference; } \\
f_{i r} \text { - movement frequency of rolling } \\
\text { elements relative to the inner ring } \\
\text { working surface; } \\
f_{r e}-\text { the rotation frequency of rolling } \\
\text { elements relative to the inner ring } \\
\text { working surface; } \\
k_{2}-\text { the ratio of the working surface } \\
\text { circumference of the inner ring to the } \\
\text { rolling elements circumference. }\end{array}$} \\
\hline $\begin{array}{l}\text { 1.Rotation frequency of } \\
\text { the separator around the } \\
\text { shaft center }\end{array}$ & Separator's wear & $f_{s}=f_{r} \cdot R_{i r} / 2 \cdot\left(R_{i r}+r_{s}\right)$ & \\
\hline $\begin{array}{l}\text { 2. Rotation frequency of } \\
\text { rolling elements relative to } \\
\text { the outer ring }\end{array}$ & $\begin{array}{l}\text { Cavity on the outer } \\
\text { ring, different sizes } \\
\text { of rolling elements }\end{array}$ & $f_{o r}=f_{s} \cdot Z_{R} \cdot k_{1}$ & \\
\hline $\begin{array}{l}\text { 3. Rotation frequency of } \\
\text { rolling elements relative to } \\
\text { the inner ring }\end{array}$ & $\begin{array}{l}\text { Cavity on the } \\
\text { working surface of } \\
\text { the inner ring }\end{array}$ & & \\
\hline \multirow{2}{*}{$\begin{array}{l}\text { 4. Rotation frequency of } \\
\text { the rolling element (all } \\
\text { elements) around its own } \\
\text { axis }\end{array}$} & \multirow{2}{*}{$\begin{array}{l}\text { Cavity on the } \\
\text { rolling elements }\end{array}$} & $f_{c l}=f_{p} \cdot R_{i r} / 2 \cdot r_{s}$ & \\
\hline & & $f_{c 2}=f_{r} \cdot R_{i r} / 2 \cdot r_{s} \cdot Z_{R}$ & \\
\hline $\begin{array}{l}\text { 5. The rotation frequency } \\
\text { of the rolling elements with } \\
\text { the outer ring skew }\end{array}$ & Outer ring skew & $f_{r s}=2 \cdot f_{s} \cdot Z_{R}$ & \\
\hline
\end{tabular}




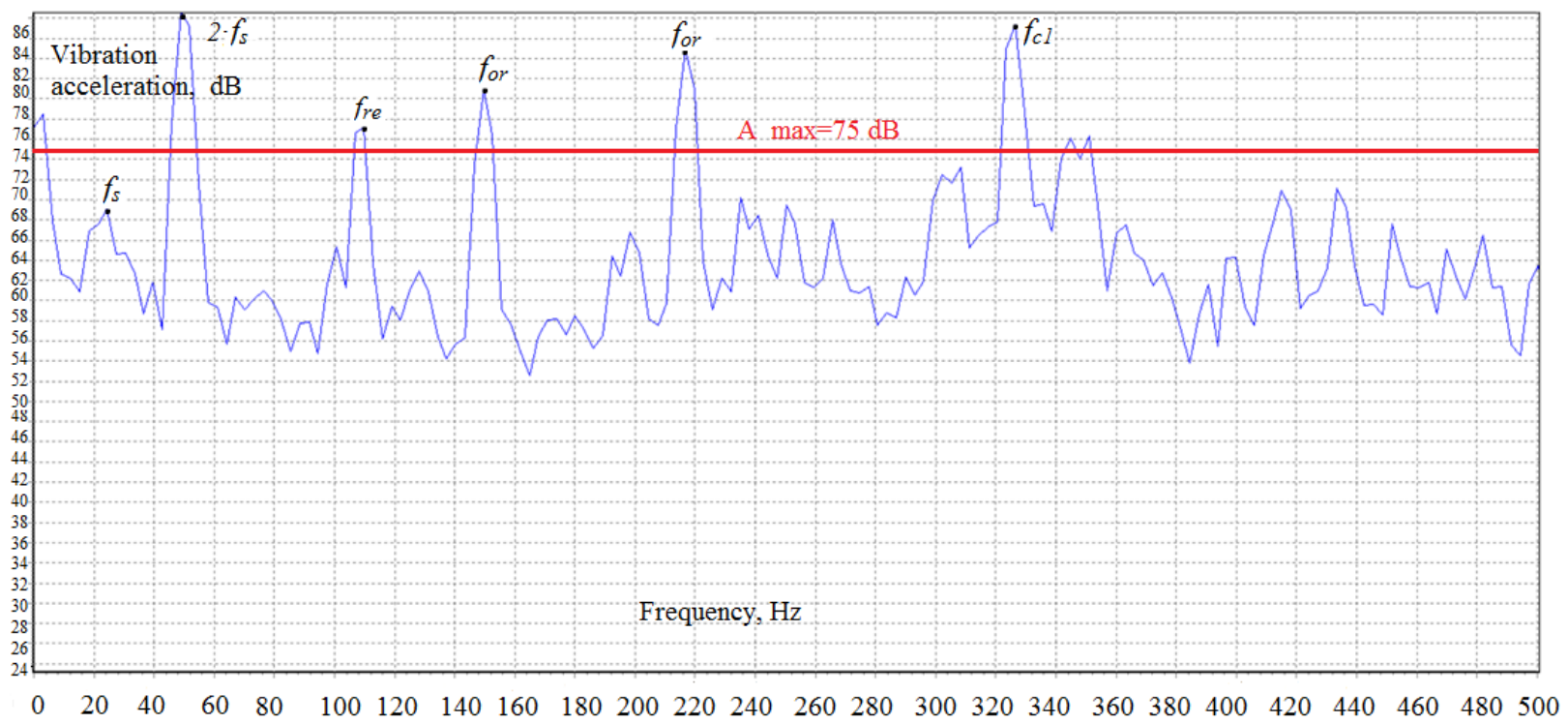

Fig. 2. The spectrum of bearing vibration №309.

Table 2. Vibration spectra and defect protocol of rolling bearing № 309 .

\begin{tabular}{|c|c|c|c|c|c|l|c|}
\hline $\begin{array}{c}\text { Numbe } \\
\mathrm{r}\end{array}$ & $\begin{array}{c}\text { Frequency, } \\
\mathrm{Hz}\end{array}$ & $\begin{array}{c}\mathrm{A}_{\min }, \\
\mathrm{dB}\end{array}$ & $\begin{array}{c}\mathrm{A}_{\text {cur, }}, \\
\mathrm{dB}\end{array}$ & $\begin{array}{c}\mathrm{A}_{\max }, \\
\mathrm{dB}\end{array}$ & Wear & Defect & Risk level \\
\hline 1 & 24.400 & 64.00 & 67.614 & 75.00 & Normal & Balance defect & 0.329 \\
\hline 2 & 48.800 & 64.00 & 77.540 & 75.00 & Emergency & Inner circle is oval & 1.231 \\
\hline 3 & 110.961 & 64.00 & 77.183 & 75.00 & Emergency & Defect of inner circle & 1.198 \\
\hline 4 & 152.00 & 64.00 & 82.00 & 75.00 & Emergency & Cavity on the outer ring & 1.63 \\
\hline 5 & 220.00 & 64.00 & 84.00 & 75.00 & Emergency & Cavity on the outer ring & 1.81 \\
\hline 6 & 325.669 & 64.00 & 87.00 & 75.00 & Emergency & Defect of rolling parts & 1.83 \\
\hline
\end{tabular}

technical condition. Possible residual resource is estimated to 20000-30000 hours. This situation can be mainly found at the enterprises where the repair services do not have vibration diagnostics and adjustment groups (table 3).

Table 3. Quality control results of new bearings.

\begin{tabular}{|c|c|c|}
\hline \multirow{2}{*}{ Condition of bearings } & \multicolumn{2}{|c|}{ Vibration frequency range, $\mathrm{Hz}$} \\
\cline { 2 - 3 } & $0-500$ & $600-5000$ \\
\hline Usable & $43(69.4 \%)$ & $30(48.4 \%)$ \\
\hline Not usable & $14(22.6 \%)$ & $29(46.8 \%)$ \\
\hline Conditionally usable & $5(8 \%)$ & $3(4.8 \%)$ \\
\hline Total, pc & $62(100 \%)$ & $62(100 \%)$ \\
\hline
\end{tabular}

When diagnosing new bearings (19 bearing plant sample) of the chemical enterprise (table 3 ), it was found that in the range of $5-500 \mathrm{~Hz} 69.4 \%$ of the sample were recognized as serviceable. In the range of $500-5000 \mathrm{~Hz}$ $48.4 \%$ of bearings are considered to be serviceable due to the low class of machining accuracy and unacceptably high vibration level.

Experiments were conducted to reduce the influence of microwaves of rolling bearing's surface on their vibration level and their length of service using various lubricants (Figure 3). The methodology of the experiment included several steps [15]:

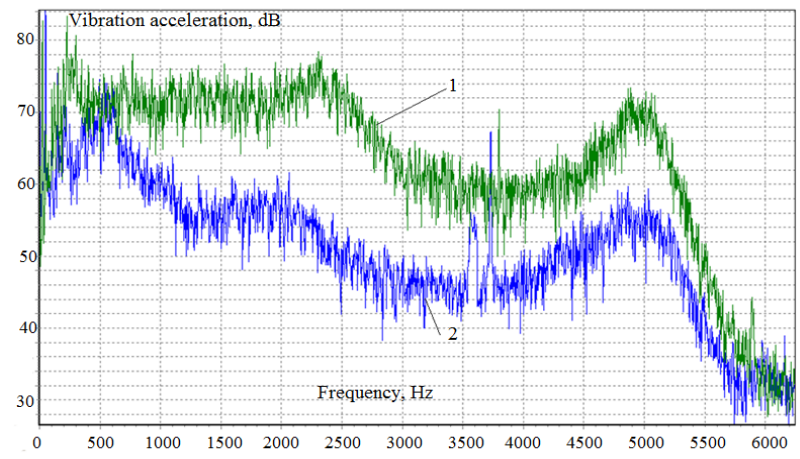

Fig. 3. Vibration diagnostics (frequency up to $5000 \mathrm{~Hz}$ ): $1-$ bearing № 409 before processing (recovery); 2 - after processing $(\mathrm{t}=25 \mathrm{~min})$ and lubricant MANNOL LC-2.

1) removing the primary vibroacoustic characteristics (spectrum 1, Figure 3);

2) removal of factory lubracant using diesel fuel;

3) preparation of a mixture consisting of glycerol and abrasive material (5-10 microns);

4) lubrication with a mixture of the circumference of the bearing race rings;

5) creating a uniform load of about $1 \mathrm{~kg}$ and ensuring the frequency of rotation of the $24,4 \mathrm{~Hz}$ inner race for 25-30 minutes with a $60^{\circ}$ movement of the outer race relative to the inner every $5 \mathrm{~min}$; 
6) washing glycerin out of the rolling bearing with abrasive powder using diesel fuel;

7) laying a lubricant MANNOL LC-2, OI MOL KSC WR2, Litol-24 and ensuring a given frequency of rotation of the inner race for 25-30 minutes;

8) repeated removal of the vibroacoustic characteristic (spectrum 2, Figure 3).

After removing the old lubricant and filling the new lubricant, the vibration of the old bearing was significantly reduced (spectrum 2, Figure 3 ).

\section{Conclusions}

Industrial enterprises bear huge losses from both the poor quality of new rolling bearings coming to the enterprises (due to the lack of input control), and bearing removal during the repair of technically serviceable bearings with a large residual life.

Modern methods of technical diagnostics, supplemented by appropriate equipment and software products, will allow to repair electric motors not according to the regulations, but according to the results of diagnosis, and secondly, to significantly reduce the cost of electrical equipment operation.

\section{References}

[1] Technical code of the designer 181-2009 (02230). Rules of technical use for consumer power installments, Minsk.-325 (2009)

[2] B.T. Holm-hansen, R.X. Gao, Structural design and analysis for a sensor-integrated ball bearing / Finite elements in analysis and design 257-270 (2000)

[3] R. Kollakot, Diagnostics of dambages : translated from English. Moscow, Mir 512 (1989)

[4] E.I. Gracheva, Estimation of electric power losses in low-voltage switching devices // News of higher educational institutions. Energy problems 74-81 (2009)

[5] A.A. Shpiganovich, K.A. Pushnitsa, E.V. Churkina, O.V. Fedorov, Features of the operation of power supply systems of ferrous metallurgy enterprises // Ferrous metals. 5, 56-61 (2017)

[6] N.V. Hruntovich, Installation, commissioning and use of electrical equipment. - Minsk. 271 (2013)

[7] E.I. Gracheva, O.V. Naumov, R.R. Sadykov, Processing of statistical information in order to identify the laws of changes in the reliability parameters of equipment for workshop networks // News of Higher Educational Institutions of the Black Earth Region. -2, 34-43 (2016)

[8] O.V. Fedorov, Estimates of the effectiveness of variable frequency drives 144 (2011)

[9] A.V. Barkov, A.V. Barkova, A.Y. Azovtsev, Monitoring and diagnosis of rotary machines by vibration. 159 (2000)

[10]N.V. Hruntovich, I.V. Petrov, Means of vibrodiagnostics of rotary machines. Agricultural technique and power supply 8(4), 40-50 (2015)

[11] N.V. Hruntovich, A.A. Alferov, P.M. Kolesnikov, Typical errors in vibrodiagnostics of power equipment. GSTU Bulletin 1, 72-81 (2010)
[12] Y.P. Aslamov, I.G. Davidof, Sparse wavelet vibrating signal decomposition for pattern recognition task. PSU Bulletin, 12, 12-23 (2018)

[13] A.V. Doronichev, K.V. Konstantinov, Expert system for vibrodiagnosting rotating bearings status and repair planning in connection with current technical conditions on the basis of wavelet-technologies introduction in the field railway transportation objects. Modern technologies, System analysis, Modeling 1(29), 92-95 (2011)

[14] A.M. Panfilov, I.V. Petrov, N.V. Hruntovich, Software application for rolling bearings study. In: Modern mechanical engineering, Gomel, 87 (2018)

[15] N.V. Hruntovich, I.V. Petrov, D.V. Kirdishev, Hypocycloid vibration frequency of rolling bearings. In: «Modern issues of energy saving and energy efficiency in technical systems», Tambov 288-289 (2016) 